\title{
A “MISÉRIA DO HISTORICISMO” E SUA DESCONSTRUÇÃO NA FILOSOFIA DA HISTÓRIA DE WALTER BENJAMIN
}

\author{
Jossilane de Sousa Freitas ${ }^{1}$ \\ "Um acontecimento vivido é finito, ou pelo menos encerrado na esfera do \\ vivido, ao passo que o acontecimento lembrado é sem limites, porque é \\ apenas uma chave para tudo que veio antes e depois". \\ Walter Benjamin
}

\section{RESUMO}

A investigação da cultura no estágio atual leva Benjamin a constatar a pobreza de experiência da humanidade, que transformou a cultura em barbárie, a despeito de todo desenvolvimento científico. O olhar crítico ao conceito de História Oficial, deduzido do progresso técnico, revela a necessidade da criação de um conceito de história que sobreviva à realidade da barbárie, apontando para um desfecho messiânico.

Palavras-chave: História. Progresso. Ruptura. Barbárie.

\section{THE “MISERY OF HISTORICISM” AND ITS DECONSTRUCTION IN THE PHILOSOPHY OF HISTORY OF WALTER BENJAMIN}

\begin{abstract}
The research culture at this stage leads Benjamin finds the poverty experience of mankind, that transformed the culture in barbarism, despite all scientific development. The critical concept of the Official Story, deduced from technical progress, the need to create a concept of history that survive the reality of barbarism, pointing to a messianic denouement.
\end{abstract}

Keywords: History. Progress. Break. Barbarism.

No mundo moderno, o progresso é visto de forma linear, como símbolo de desenvolvimento da humanidade. Por essa óptica nossa geração será menos desenvolvida do que as vindouras. Seus instrumentos serão mais atualizados, mais avançados. Mas será que esta evolução acompanha também um desenvolvimento linear da humanidade? Desenvolvimento este propriamente humano, ou seja, que fala de características e valores que só existem enquanto "seres humanos" dotados de razão e sentimento?

\footnotetext{
1 Jossilane de Sousa Freitas é graduanda em Filosofia na Universidade Estadual do Ceará.
} 
Podemos negar deste modo que exista um progresso destes instrumentos tecnológicos e de informação? Não, Mas quando nos perguntamos da sua utilidade para além da nossa vida prática, para além dos artifícios tecnológicos, que resposta obtemos? É inegável que a facilitação de informação, o desenvolvimento de instrumentos e aplicativos nos auxiliam muito na resolução dos problemas e atividades do nosso dia-a-dia. Fica claro e irrefutável que a evolução dos meios tecnológicos existe, mas cabe a nós refletirmos sobre os dois lados do questionamento.

Este texto nos fará refletir sobre a resposta à pergunta: Que "preço" estamos pagando pelo desejado progresso? O que este nos trouxe? Evolução e desenvolvimento ou evolução e decadência? De que forma decadência? Isso não é contraditório? É, e é por isso que discutiremos igualmente a evolução e o retrocesso da civilização, tomando como base a reflexão benjaminiana da história como um enigma (als Rätselfrage) $)^{2}$.

Partindo dessa interrogação o filósofo judeu alemão Walter Benjamin ${ }^{3}$ analisa as "duas faces" do progresso, mostrando que este também possui o seu lado degenerado que se constata na própria história da humanidade. É preciso apenas que visualizemos por debaixo da camada de maquilagem que apresenta a história em sua face sedutora, que nos fez adormecer por tanto tempo e pregar, defender e desejar o que estar por vir.

A filosofia da história de Benjamin tem por objetivo reconstruir os conceitos de história e progresso, estes entendidos agora não mais como história progressista, mas como um desenvolvimento que tem por fim a utopia da ciência funestamente

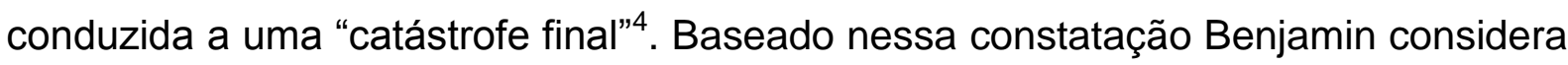
o desenvolvimento tecnológico que levou "à prática da social-democracia determinada por um "conceito dogmático de progresso sem qualquer vínculo com a

2 BENJAMIN. Origem do drama barroco alemão, Tradução de Sérgio Paulo Rouanet, São Paulo: Brasiliense, 1984, p. 188.

3 Viveu entre 1892 á 1940 . Sua multidisciplinaridade, concretizada em um saber de diversas áreas tais como teologia, linguagem, literatura, cinema, educação, antropologia, teoria crítica e arte, tem uma história de influências e reflexos que se estende da psicanálise de Freud, às críticas ao complexo capitalista burguês da tradição marxista, além do conhecimento da mística judaica. Todos esses contatos não tiveram interferências na originalidade e autenticidade de um pensamento votado à análise crítica da Modernidade., deixando que despontem para serem rompidas as arestas da cultura transformada em barbárie. A despeito de todo progresso e do deslumbramento despertado por ele.

4 BENJAMIN. Origem do drama barroco alemão, Tradução de Sérgio Paulo Rouanet, São Paulo: Brasiliense, 1984, p. 90. 
realidade" ${ }^{5}$, em que a História desvela a sua "facies hippocratica" 6 , isto é, o seu lado degenerado, torpe, provocado pelo poder que se tornou violência. O livro sobre a dramaturgia barroca Trauerspielbuch escrito por Benjamin já alude à queda do homem ético (das Versinken des sittlichen Menschen) ${ }^{7}$. O fenômeno da degeneração histórica (a que Benjamin chamou de naturalização da história), onde ele viu plasmada a degeneração natural do homem com base no conceito de physis culpada, foi caracterizado como perda do ethos histórico. ${ }^{8}$ Isso mesmo! O Progresso movido pela ciência que apareceu no contexto da violência é compreendido por Benjamin enquanto catástrofe: "Deve-se fundar o conceito de progresso na ideia de catástrofe. Que tudo continue assim. Isto é a catástrofe. Ela não é o sempre iminente, mas sim o sempre dado"9. Para reverter essa situação. Benjamin lança mão da imagem dialética apelando para a força messiânica que nos é transmitida pelas gerações anteriores. Pois o que a ciência constatou a memória pode modificar. A parada messiânica tem a precedência da memória. representa uma ruptura na evolução histórica que nos conduz ao pior e tem o objetivo de sugerir um atalho para uma reflexão que possa ser salvadora. Para entendermos melhor de que se fala aqui, faremos uma avaliação do processo pelo qual a humanidade passa nestes tempos modernos. O estudo de Benjamin sobre o barroco elucida o aspecto enigmático da história com a metáfora da face de Janus ${ }^{10}$ do monarca que remete aos dois lados da condição da criatura, a qual a história se vê vinculada pelo conceito de imanência ${ }^{11}$.

Dentre os resultados encontrados por Benjamin na sua análise da decadência da história, tem-se a destruição generalizada da "experiência", o fim da "narratividade" oral, o fetiche, o enfraquecimento da memória, como sintomas do individualismo exacerbado da Modernidade.

5 BENJAMIN, Walter. "Sobre o conceito de história", p.229, tese 13.

6 BENJAMIN. Origem do drama barroco alemão, Opus cit, 188.

7 Idem, ibidem, p. 150.

8 BENJAMIN. Origem do drama barroco alemão, Tradução de Sérgio Paulo Rouanet, São Paulo:

Brasiliense, 1984, p. 111.

9 BENJAMIN. "Parque Central" in: Charles Baudelaire um lírico no auge do capitalismo,Tradução de José Carlos Martins Barbosa e Hemerson Alves Baptista, São Paulo: Brasiliense, 1989, p.174.

${ }^{10}$ BENJAMIN. Origem do drama barroco alemão, Opus cit, p. 93.

${ }^{11}$ Como a falta da transcendência, "obstruída" através do rigor da moral luterana a mentalidade do século XVII barroco tem uma percepção aguçada para o sentido imanente da própria existência. Isso leva o barroco a desenvolver o carpe diem (chora o tempo que passou. ele não volta mais). BENJAMIN. Origem do drama barroco alemão, Opus cit, p.103. 
No ensaio Experiência e pobreza, de 1933, Benjamin utiliza a parábola de um velho transmitindo, antes de morrer, certo ensinamento aos seus filhos, para nos apresentar um dos conceitos mais fundamentais de sua filosofia, a Erfahrung ${ }^{12}$, ou seja, a experiência, conjunto de valores adquiridos pela vida que são compartilhados entre as gerações. Seu objetivo é interrogar sobre o declínio da experiência, seus motivos e sua possível recuperação:

\begin{abstract}
Sabia-se exatamente o significado da experiência: ela sempre fora comunicada aos jovens. De forma concisa, com a autoridade da velhice, em provérbios de forma prolixa, com a sua loquacidade, em histórias, muitas vezes como narrativas de países longínquos diante da lareira, contadas a pais e netos. Que foi feito de tudo isso? Quem encontra ainda pessoas que saibam contar histórias como elas devem ser contadas? Que moribundos dizem hoje palavras tão duráveis que possam ser transmitidas como um anel, de geração em geração? Quem é ajudado, hoje, por um provérbio oportuno? Quem tentará sequer, lidar com a juventude invocando sua experiência? ${ }^{13}$.
\end{abstract}

Nesta citação, Benjamin denota a pobreza que atingiu as novas gerações em uma realidade desvinculada dos valores da tradição. Por que isso acontece? Seria a falta de experiências vividas? Não, esta mesma geração "viveu uma das mais terríveis experiências da história". A causa desta miséria deve-se ao exorbitante desenvolvimento da técnica que se instaurou em nossos tempos, e que "não foi suficientemente forte para dominar as forças elementares da sociedade"14. A experiência vivida no campo de batalha nas guerras entre 1914 e 1918 apenas tornou os indivíduos mais miseráveis, "mais pobres em experiências comunicáveis, e não mais ricos" ${ }^{\prime 15}$.

Uma das consequências do declínio da transmissão de experiências memoráveis está no desaparecimento da figura do narrador, do espaço da comunidade, sendo esta substituída por outra lógica de agrupamento que é a sociedade. No ensaio O Narrador - Considerações sobre a obra de Nicolai Leskov de 1936, Benjamin mostra que "a arte de narrar está definhando porque a sabedoria - o lado épico da verdade está em extinção". ${ }^{16}$ A faculdade de intercambiar experiências, que acontecia na comunidade, está em declínio. Sua causa? As

\footnotetext{
${ }^{12}$ Benjamin entende que a Experiência (Erfahrung) encontra-se em declínio BENJAMIN, Walter. Experiência e Pobreza. In: _ Magia e Técnica Arte e Política Tradução Sérgio Paulo Rouanet, São Paulo: Brasiliense, 1985, p.114-119..

${ }^{13}$ BENJAMIN, FALTA A OBRA, INCLUSIVE NAS REFERÊNCIAS. 1985, p. 114.

${ }^{14}$ BENJAMIN. "Teorias do fascismo alemão "in Magia e Técnica, Arte e Política. Opus cit, p. 61.

15 "BENJAMIN. "Experiência e Pobreza", Opus cit, p. 115.

${ }^{16}$ BENJAMIN, FALTA A OBRA, INCLUSIVE NAS REFERÊNCIAS. 1985, p. 201.
} 
experiências também estão em baixa. O mundo sofreu muitas transformações em um espaço de tempo muito curto, sem dar tempo às pessoas de digerir a mudança.

\begin{abstract}
Uma geração que ainda fora à escola num bonde puxado por cavalos viu-se abandonada, sem teto, numa paisagem diferente em tudo, exceto nas nuvens, e em cujo centro, num campo de forças correntes e explosões destruidoras, estava o frágil e minúsculo corpo humano. ${ }^{17}$
\end{abstract}

Ao término da guerra notou-se que os indivíduos voltaram do campo de batalha mudos, silentes, pobres em experiências transmissíveis pelo discurso vivo. O desenvolvimento desenfreado dos artifícios e meios tecnológicos foi um fenômeno determinante para o enfraquecimento da arte de narrar histórias. Na experiência da narrativa, o narrador é dotado de autoridade, sabe dar conselhos, transmitir ensinamentos e valores. Não se constrange com isso. Ao contrário, se enobrece de poder fazê-lo. Mas como pensar a figura do narrador em uma época que não preserva mais a tradição? É por isso que sua trajetória está com os dias contados, porque a "fonte da qual recorrem todos os narradores é a experiência que passa de pessoa a pessoa"18 , e que já não existe mais. A memória era a fonte inesgotável de onde provinha a sabedoria acumulada entre as gerações e que sedimentava a autoridade conferindo ao mesmo tempo veracidade ao que era narrado. Com o empalidecimento da memória vai se enfraquecendo igualmente a narrativa que tinha como estofo a experiência de épocas passadas, sedimentadas na tradição de muitos povos. Ao contrário do narrador que sempre tinha como ouvintes futuros narradores, o homem moderno apenas conhece a individualidade e no lugar da experiência ele só pode se guiar pela vivência do choque que o faz despertar para uma realidade estéril uma vez desaparecida a transmissão de saberes e a noção de comunidade, onde se desenvolviam os laços afetivos. Ao contrário da segurança da tradição dos valores comprovados pela prática, a tecnologia supre de aventuras oníricas aos habitantes da metrópole na realidade da fantasmagoria da vitrine, apelando para o consumo que faz o papel de único elemento apaziguador diante do choque cotidiano. $E$ lhe dá a impressão de progresso e de bem estar, massageia o ego dos passantes. Para Benjamin o que podemos na verdade aprender com o choque é o despertar $^{19}$, através da percepção estimulada pelas sensações visuais, auditivas,

\footnotetext{
${ }^{17}$ BENJAMIN. Origem do drama barroco alemão, 1984, p.115.

${ }^{18}$ BENJAMIN. Idem, ibidem, p. 198.

19 "O agora da cognoscibilidade é o momento do despertar", BENJAMIN. Passagens, Tradução de Willi Bolle et allii, Belo Horizonte: Humanitas, 2006, p. 528
} 
táteis. O habitante da cidade tem a sensação do conforto no interior burguês, o que não passa de uma ilusão. No dia-a-dia da cidade grande, em cujos recantos espreita o perigo, a necessidade de defesa é iminente. A cidade ilude. "[Ela] é a realização do antigo sonho humano do labirinto" ${ }^{20}$. Assim se dirige Baudelaire através de sua poesia ao esgrimista. A urgência em esgrimir com a realidade e que faz parte do choque é comparada com o trabalho do poeta que precisa vender sua poesia como mercadoria para sobreviver enquanto ao narrador cabe a felicidade de passar adiante sua sabedoria e com ela fortalecer os valores da tradição através da oralidade e pela própria experiência. O fim da arte de narrar é o limite de uma existência, cujas atividades artesanais se desenvolviam simultaneamente à transmissão de experiências vividas na comunidade, caracterizada pela troca de saberes, e ao mesmo tempo marca a vivência com o choque (Chockerlebnis), na realidade da barbárie em uma cultura que não preserva mais os elementos que fornecem a possibilidade do conhecimento das verdadeiras experiências, mas os apaga, pois a tecnologia provê o habitante da cidade de espaços assépticos, iluminados de vidros que ofuscam e onde não se vê mais necessidade da memória. As casas de vidro não têm aura. Não guardam nenhuma lembrança, não permitem marcas, como a madeira. Elas são ilesas aos vestígios humanos, não viabilizam a reminiscência (Eingedenken), que para os antigos, funda a cadeia da tradição ${ }^{21}$. A existência na Modernidade apaga todos os rastros até os da morte. $O$ vidro denuncia, vigia, sem deixar que nada se fixe, nem mesmo os sinais do passado. Nossa cultura de vidro é marcada pelo esquecimento:

A barbárie está inserida no próprio conceito de cultura: como conceito de um tesouro de valores considerado de forma independente, não do processo de produção na qual nasceram os valores, mas do processo no qual eles sobrevivem. ${ }^{22}$

Diante dessa barbárie, Benjamin nos convida a construir um "conceito novo e positivo de barbárie". Nossa proposta deve ser ir em frente e começar do novo, "construir com pouco, sem olhar nem para a direita, nem para a esquerda" ${ }^{23}$. Essa decisão se fundamenta na possibilidade de recuperar o perdido, de resgatar a memória através da interpretação, de realizar a revolução-redenção da humanidade.

\footnotetext{
${ }^{20}$ BENJAMIN. "O Flâneur" in:_Charles Baudelaire um lírico no auge do capitalismo Tradução de José Carlos Martins Barbosa e Hemerson Alves Baptista, São Paulo: Brasiliense, 1989, p. 203.

${ }^{21}$ BENJAMIN. "O Narrador", Opus cit, p. 211.

${ }^{22}$ BENJAMIN. Passagens, 2006, p. 509.

${ }^{23}$ BENJAMIN. "Experiência e Pobreza", p.116.
} 
Para isto é preciso antes que assumamos nosso estado atual de pobreza, para que possamos começar do novo, pois "os homens aspiram libertar-se de toda experiência, aspiram a um mundo em que possam ostentar tão pura e tão claramente sua pobreza externa e interna, que algo de descente possa resultar disso" 24 .

Ao negar o conceito de progresso, em que a cultura está inserida Benjamin não está minimizando a capacidade do gênero humano para a mudança, para a recriação, mas criticando os pressupostos da criação, pela dialética hegeliana, de um conceito de "perfectibilidade infinita do gênero humano" 25 buscada na razão enquanto espírito em si e amplamente alardeada nas teorias da história. O filósofo alemão busca resgatar os valores humanitários, pois a ideia histórica como processo linear e contínuo administrado pelo conceito de razão humana e que gerou a instrumentalização da ratio - realizada com a ciência transformada em tecnologia a serviço dos dominadores - provou ser aniquiladora da própria razão individual. Acrescenta-se a esse fenômeno histórico a evidência de que "a realidade social na Modernidade não está madura para transformar a técnica em seu órgão" 26 .

Esse conceito tradicional, Erfahrung não mais se sustenta na Modernidade. Como foi dito o seu espaço vazio foi ocupado pela Erlebnis, a mera sensação diante dos acontecimentos. A vivência do homem da Modernidade com o choque ${ }^{27}$ está condicionada a mera sensação diante dos acontecimentos, A vivência é estimulada pelo Choque (Chocherlebnis). Com o desaparecimento do sujeito lógico, analítico transcendental na realidade da fragmentação dos valores da tradição que garantiam a sobrevivência anímica e afetiva, a existência se viu mergulhada nas contingências da efemeridade, (da condição de mortal, segundo a óptica do barroco) e essa verdade longe do "apoio da religião objetiva" 28 como diz Adorno, precipita o habitante da cidade na busca de paliativos como o trabalho e o lazer, onde ele busca dissuadir-se do vazio aberto com o fim das experiências que formavam a

\footnotetext{
${ }^{24}$ BENJAMIN. Idem, ibidem, p.118.

${ }^{25}$ BENJAMIN. "Sobre o conceito de história", Opus cit, p. 229.

${ }^{26}$ BENJAMIN. "Teorias do fascismo alemão", Opus cit, p. 61.

27 Adorno atribui à " tecnificação" da existência a mudança de gestos, no homem. À violência, que segundo Adorno, já é intrínseca à técnica, é a grande causadora da "existência danificada". Pois ela provoca, no aparelho psíquico do homem, uma cadeia de choques, na realidade da Metrópole moderna. ADORNO, "Entre sem bater" in:__Minima moralia, Tradução de Gabriel Cohn, Rio de Janeiro: Azougue, 2008, p. 36.

${ }^{28}$ ADORNO, A indústria cultural O Esclarecimento como mistificação das massas in:__ética do Esclarecimento, Tradução de Guido Antônio de Almeida, Rio de Janeiro: Editora Zahar,1985, 113.
} 
cadeia de conhecimento compartilhado. Dissipou-se da mesma forma a relação com o mundo natural ${ }^{29}$. O campo migrou para a cidade em forma de fetiche. A relação do homem com o cosmo se enfraqueceu quando a ciência encetou sua investigação vasculhando o cosmo como uma peça de laboratório. No lugar da harmonia entre homem e cosmo está a robotização, o automatismo. Esta é a caracterização da denominada cultura de vidro em que vivemos. Sua visibilidade absoluta tornou as pessoas obcecadas pela novidade, e simultaneamente individualistas e solitárias, precisando recorrer à astrologia, ao espiritismo, a ioga e outras tentativas de renovação para não se angustiarem com o "tempo vazio e homogêneo" ${ }^{30}$ em que a repetição infernal dos objetos de consumo está a serviço do lucro dos dominadores.

Assim, já que a experiência autêntica (Erfahrung) deu espaço para a vivência do choque (Chocherlebnis), é dela que partiremos na tentativa de apreender as lições de uma nova forma de compreensão da história pensada por Benjamin. Como não é mais possível a reconstrução da história sobre o conceito de Experiência, Benjamin vai recorrer a vivência (Erlebnis). Compreendendo o desenvolvimento de relações efêmeras e instantâneas estimuladas pelo choque, o filósofo reconhece nele o estímulo das sensações que levam ao despertar ${ }^{31}$ com a dilatação da percepção no espaço da fantasmagoria da metrópole moderna.

Com o exemplo das experiências surrealistas é possível reconhecer na história os lampejos da verdade. Benjamin via no surrealismo uma nova forma de politização. Sendo sua matéria prima o inconsciente, esse movimento se aproximava do seu método de investigar o fato histórico, ou seja, possuía a dialética como meio de captar o aqui e o agora do momento histórico, sua autenticidade.

\footnotetext{
Pensar é algo que abrange não só o movimento das ideias como a imobilização delas. Quando o pensamento se detém, subitamente, numa constelação saturada de tensões, ele lhe transmite um choque através do qual e cristaliza como mônada. O materialismo histórico só consegue se aproximar de um objeto histórico quando consegue se diferenciar com ele como mônada. ${ }^{32}$
}

\footnotetext{
${ }^{29}$ O ensaio "Teorias do fascismo alemão" traça o limite da relação homem e cosmo. A mobilização, pelo Estado, das" forças mágicas" que antes regiam aquele elo natural, é canalizada na criação de um conceito falso de "heroísmo de guerra" (com o objetivo de inflamar o ânimo dos soldados) mas que é incompatível com a guerra de materiais, que caracterizou a natureza da guerra assessorada pela técnica. BENJAMIN, "Teorias do fascismo alemão", Opus cit, p. 71.

${ }^{30}$ BENJAMIN. "Sobre o conceito de história", Opus cit, p. 229

${ }^{31}$ BENJAMIN. "Sobre o conceito de história", Opus cit, p.230.

${ }^{32}$ BENJAMIN. Origem do drama barroco alemão, 1984, p.231.
} 
Fica notável nesta passagem a importância que a imagem dialética apresenta para a redenção histórica em Benjamin. Na tese, o filósofo objetiva apresentar como método contra o tempo homogêneo e vazio da linearidade histórica, uma imagem dialética para desacelerar o movimento insensato e vertiginoso como encontramos no sistema hegeliano. Para cessar a "marcha de catástrofes" da história, Benjamin propõe uma revolução que tem por objetivo essa pausa (Dialektik im Stillstand) ${ }^{33}$. Aos olhos de Benjamin, a dialética da imobilidade recupera a singularidade desses objetos históricos, interpretados muitas vezes de forma equivocada. Para Benjamin o que a "ciência estabeleceu pode ser modificado pela rememoração. Esta pode transformar o inacabado (a felicidade) em algo acabado e o acabado (o sofrimento) em algo inacabado. Isso é teologia"34. Pois "a autêntica concepção do tempo histórico baseia-se inteiramente na imagem da redenção"35.

Sendo essa força do progresso catastrófica, uma tempestade de ruínas, devemos "fazer explodir o continuum da história, próprio das classes revolucionárias no momento da ação ${ }^{36 " . ~ E s t a ~ e ́ ~ u m a ~ a t i v i d a d e ~ p r o ́ p r i a ~ d a s ~ c l a s s e s ~ r e v o l u c i o n a ́ r i a s ~}$ que se libertarão e farão justiça às gerações passadas de vencidos, assim, são os oprimidos que se colocam como sujeito do conhecimento, que tomam consciência e alcançam a verdade mascarada por falsos conceitos.

Vê-se claro neste momento de investigação que: se nos faltam conceitos que sejam coerentes com a realidade, devemos pensar e formular outros novos. É isso que a filosofia de Walter Benjamin objetiva, formular um novo conceito que possibilita uma nova forma de visibilidade da construção histórica.

Nesta busca pela verdade, da história e da humanidade e o esforço de reconceituar a história, Benjamin escreve as 18 teses de Sobre o conceito de história de 1940. O ensaio nos oferece a possibilidade de pensarmos uma nova concepção de história fundamentada não mais sobre a ideologia dominante em que está configurada a historiografia oficial, mas em um conceito que busca a verdade e se constrói pelas vozes silenciadas no passado.

A primeira tese descreve um mecanismo em que um fantoche turco sentado em uma mesa de xadrez, aparentemente toda visível em cada pormenor, ganha

\footnotetext{
${ }^{33}$ Dialética na Imobilidade

${ }^{34}$ BENJAMIN. "Teoria do Conhecimento, teoria do progresso" in:__ Passagens. Opus cit, p. 513.

35 Idem, ibidem, p. 521

${ }^{36}$ BENJAMIN, Walter. "Sobre o conceito de História ", p.230.
} 
sempre. Entretanto, o que não se sabe é que por debaixo da mesa existe um anão corcunda, que na verdade é o grande mestre no xadrez. Assim, Benjamin associa o fantoche ao materialismo histórico e o anão corcunda à teologia. O que Benjamin pretende, ao nos contar essa história, é mostrar que mesmo o materialismo histórico possuindo a aparência de vencedor, é a teologia a grande responsável por todas as vitórias.

Segundo a noção do materialismo histórico, a história da sociedade humana culmina com a história da luta de classes, da relação entre exploradores e explorados, dominantes e dominados. Diferente desse marxismo evolucionista vulgar que defende a evolução histórica dependente do processo econômico e técnico, Benjamin vê no progresso uma marcha de catástrofe, por isso procura reconstruir o conceito de progresso enquanto parada messiânica, interrupção, uma ruptura de uma evolução histórica que nos conduz ao pior.

O diferencial da filosofia de Walter Benjamin está na imagem dialética que permite ver por trás do materialismo história a atuação da teologia, ou melhor, o seu caráter messiânico de trazer o bem para a humanidade. Somente a união de ambos poderá fazer jus as gerações passadas, para que o presente, consciente de sua história, aceite o apelo do passado e o salve para as gerações posteriores.

Benjamin defende que existe um caráter dentro da teologia, no caso, o caráter messiânico que ajudaria no entendimento da história. Ou seja, o que Benjamin propõe é unir ao materialismo histórico este espírito messiânico da teologia, para que assim a humanidade não se deixe levar pelas ideias de um materialismo histórico ortodoxo embutido no aparelho psíquico dos indivíduos, alimentando o conformismo diante da noção dominante-dominado, vencedor- vencido. materialismo histórico deve assim aprender a colocar a seu serviço os valores trazidos pela teologia para alcançar a revolução-redenção.

Benjamin pensa que assim como o historiador marxista não perde de vista a luta de classes pelas coisas materiais, este também não deve deixar-lhe escapar as coisas espirituais. "Elas se manifestam nessa luta sob a forma da confiança, da coragem, do humor, da astúcia, da firmeza, e agem de longe, do fundo dos tempos. Elas questionarão sempre cada vitória dos dominadores"37.

\footnotetext{
${ }^{37}$ Idem, ibidem, p. 224.
} 
Estes valores nos quais as coisas espirituais se manifestam são menos visíveis e atribuídas ao vencedor e não ao vencido a quem pertencem de direito. Daí porque Benjamin salienta a importância de um alerta do materialismo histórico que deve estar sempre pronto a captar as pequenas e imperceptíveis transformações.

Benjamin nos relata sobre Fustel de Coulanges, este é um historiador que recomenda que na tentativa de reconstruir o passado de uma certa época, se esqueça tudo sobre o posterior transcurso da história. Este é o ponto segundo Benjamin que melhor caracteriza o rompimento com o materialismo histórico. Este é o método da empatia, que teve origem da inércia do coração, a acedia (indiferença) que objetiva alcançar a verdadeira imagem histórica. Tem esse nome por conta dos teólogos medievais associarem a acedia ao primeiro fundamento da tristeza. Essa ideia da acedia fica mais evidente segundo Benjamin quando nos fazemos a pergunta: "com quem o investigador historicista estabelece a relação de empatia?"38 E a resposta: "com o vencedor", mostra que os dominadores são os beneficiados.

Benjamin define como tarefa do historiador a luta contra as convenções, realizando uma leitura do passado em busca das diferenças, do particular que se perde na media conceitual, enfim dos "não ditos" pela história, dos esquecidos pois o materialismo histórico considera como tarefa sua "escovar a história a contrapelo"39. Essa é a exigência fundamental de Benjamin para criar outro conceito de história, ou seja, do ponto de vista dos oprimidos, contra a tradição conformista do historicismo em empatia com o vencedor, uma vez que o historicismo se identifica com as classes dominantes. O conceito de catástrofe de Benjamin vê a história como um encadeamento de fatos políticos e militares, sempre dando poder aos grandes dirigentes e dominadores, onde "todos os que até hoje venceram participam de um cortejo triunfal em que os senhores de hoje caminham sobre os corpos dos vencidos" diz a tese VII.

Benjamin nos convida a originar um verdadeiro estado de exceção (Ausnahmezustand) que corresponda à emancipação e libertação dos oprimidos. Fica evidente nessa decisão a crítica ao fascismo. Benjamin não vê o fascismo como um acidente da história, mas como um absurdo causado pela falta de compromisso, pela omissão e pela complacência de um povo despolitizado além de

\footnotetext{
38 BENJAMIN. "Sobre o conceito de história”, Opus cit, p. 225.

39 Idem, ibidem, p. 225.
} 
compreender sua causa na ideia de progresso e sua irracionalidade estruturada na técnica a serviço da guerra:

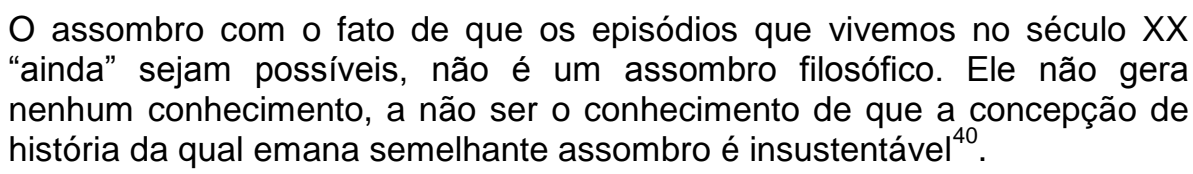

Para a criação de um novo conceito de história, é preciso relembrar a história daqueles que não aparecem na História Oficial. Recorrer à reminiscência para Benjamin é fazer justiça aos oprimidos do passado. Esse aspecto frágil da história oficial é denunciado pelo anjo da história que Benjamin associa à imagem do quadro Angelus Novus de Paul Klee. Este anjo olha fixamente algo do qual tenta afastar-se. Seu aspecto terrível, com a boca aberta e olhos arregalados mostra que a cena presenciada lhe causa horror. O seu rosto contempla o passado, e onde vemos uma série de acontecimentos, ele vê uma única catástrofe contínua, que amontoa ruínas, jogando-as a seus pés. O anjo deseja juntar os fragmentos e reorganizar os vencidos, mas é impedido por uma tempestade do progresso que o impulsiona ao futuro, enquanto à sua frente acumulam-se ruínas e ruínas até o céu.

O progresso e a crença na promessa de felicidade que este traz consigo são assim os grandes responsáveis pela permanência da concepção de história enquanto processo linear, e pelo conformismo que corrompe o pensamento fazendo de nossa época uma era de estado de exceção. A esse respeito diz Benjamin: "A tradição dos oprimidos" 41 nos ensina que o "estado de exceção" em que vivemos é na verdade a regra geral. Precisamos construir um conceito de história que corresponda a essa verdade. Benjamin percebe a necessidade de se construir um estado de exceção verdadeiro se quisermos fazer valer o conceito de história que será criado contra a tradição dos vencidos. O estado de exceção representa ir na contramão da história, descobrir o que a história contada nos livros ensina de maneira desfigurada, para poder combatê-la com a ajuda dos fragmentos significativos que testemunham a verdade. Deste modo, é necessária a luta contra o império das convenções, é preciso abolir a tradição conformista que nos dá a ilusão de bem estar social, resistir a sedução de todo monumento da cultura. Somente o despertar, movido por uma percepção política lato sensu libertará o homem da

\footnotetext{
${ }^{40}$ Idem, ibidem, 226

${ }^{41}$ BENJAMIN. "Sobre o conceito de história", Opus cit, p. 227.
} 
passividade e do conformismo, em direção a genuína e corajosa ação libertadora do agora (Jetztzeit) confluindo para a remissão da humanidade.

O passado faz um apelo ao presente, e quando isso acontece é preciso estar munido de conhecimento para deixar que a verdade se apresente. A imagem verdadeira do passado passa velozmente ${ }^{42}$, mostrando-se em um lampejo, por isso, é preciso fixar a imagem do passado no momento atual do perigo, pois este não se mostra como de fato ele foi, apenas fornece sinais fracos. Portanto, faz-se necessário o uso da força messiânica presente entre as gerações e da dialética na imobilidade (Dialectik im Stillstand) para sermos capazes de perceber nos estilhaços messiânicos recolhidos pela frágil força messiânica que cada um de nós possuímos, as imagens que o passado dirige ao presente, memorizando-os, fixando-os e imobilizando-os enquanto imagem dialética, pois "somente as imagens dialéticas são autenticamente históricas, isto é, imagens não-arcaicas” ${ }^{43}$.

Em sua filosofia da história Benjamin busca o "despertar" através do inconsciente que ele vai encontrar no Surrealismo. Em última análise, ele objetiva despertar a humanidade de seu "sonho", pois este momento coincide com o agora da cognoscibilidade ${ }^{44}$. Ou seja, será neste momento do despertar que a humanidade se verá consciente do real acontecido e da realidade em que se encontra. É no agora da cognoscibilidade que conheceremos verdadeiramente o que ficou esquecido, que passou despercebido aos olhos de um tempo que ainda estava embriagado por falsas promessas e que construiu a fantasmagoria da metrópole moderna.

\footnotetext{
42 BENJAMIN. "Sobre o conceito de história", Opus cit, p.224.

${ }^{43}$ BENJAMIN. "Teoria do Conhecimento, teoria do progresso", Opus cit, p. 505.

${ }^{44}$ Idem, ibidem, p. 505 [N 3, 1]
} 


\section{REFERÊNCIAS}

ADORNO, Theodor Wiesengrund. "A indústria cultural O Esclarecimento como mistificação das massas". In:- ética do Esclarecimento, Tradução de Guido Antônio de Almeida, Rio de Janeiro: Editora Zahar,1985, 113.

ADORNO. Theodor Wiesengrund.. "Entre sem bater". In:_Minima moralia, Tradução de Gabriel Cohn, Rio de Janeiro: Azougue, 2008

BENJAMIN, Walter. "Experiência e Pobreza". In_ Obras escolhidas l: Magia e Técnica, Arte e Política. 10 ed. Tradução: Sérgio Paulo Rouanet, São Paulo: Brasiliense, 1984.

BENJAMIN, Walter. "Teorias do Fascismo Alemão". In:- Obras escolhidas I: Magia e Técnica, Arte e Política. 10 ed. Tradução: Sérgio Paulo Rouanet, São Paulo: Brasiliense, 1984.

1984.

Origem do drama barroco alemão. São Paulo: Brasiliense, Humanitas - Editora da UFMG, 2006.

Obras Escolhidas II Rua de mão única. Trad.: Rubens Rodrigues Torres Filho e José Carlos Martins Barbosa. SP: Brasiliense, 1987.

"A obra de Arte na Era de sua Reprodutibilidade Técnica", in:__ Os Pensadores: São Paulo: Victor Civita, 1983.

KONDER, Leandro. O marxismo da melancolia. Rio de janeiro: civilização brasileira, 1999.

LOWI, Michel. A filosofia da História de Walter Benjamin. In Estudos Avançados, 16, 45, 2002.

CALLADO. Tereza de Castro. "O Jugendstil e o mito fascista do belo:oração fúnebre à Crítica" in:_Cadernos Walter Benjamin N.06, 2011. Disponível em: www.gewebe.com.br/cadernos.htm. Acesso em: 15/02/2013.

"As Metamorfoses da consciência burguesa e a imagem dialética". in: _ Cadernos Walter Benjamin. N. 04 Disponível em: www.gewebe.com.br/cadernos.htm Acesso em: 15/02/2013.

"A metafísica benjaminiana e o agora (Jetztzeit)". In: - Cadernos Walter Benjamin N. 02.- Janeiro-Junho de 2009, Disponível em: www.gewebe.com.brcadernos.htm Acesso em: 15/02/2013.

"A Teoria da Melancolia em Walter Benjamin". A versão do taedium vitae medieval e de seus elementos teológicos na concepção de melancolia do barroco" . in:__ Cadernos Walter Benjamin N.01 Julho-Dezembro de 2008. Disponível em: www.gewebe.com.br/cadernos.htm Acesso em: 15/02/2013. 